\title{
Odontometric parameters as a forensic tool for stature estimation among three Asian ethnicities
}

\author{
Bharath Rao K ${ }^{1 *} \mathbb{D}$, Madhumitha Natarajan², Arul Amalan', Runki Saran', Ravi Gupta', Saurabh Kumar², \\ Amith Sing ${ }^{2}$ and P. Kalyana Chakravarthy ${ }^{2}$
}

\begin{abstract}
Background: The height of an individual in the upright posture is referred to as stature. The evaluation of the stature of an individual is an essential step in identification. Estimation of stature is commonly performed using the long bones as they positively correlate with the stature. The correlation between the dimensions of the skull, jaw and stature of an individual has been reported among specific populations. To date, only a few studies have correlated odontometric parameters with stature among populations. Teeth and oral structures can be used to estimate the stature of an individual. The objective of our study was to determine and establish a relationship to estimate the stature of individuals among three different Asian ethnicities using four odontometric parameters as a forensic tool. The Asian ethnicities chosen in our study were Malay, Indian and Chinese.

The five parameters were the height of an individual, intercanine width, interpremolar width, arc length and mesiodistal dimension of the six anterior teeth. The height was measured with the individual standing upright and barefooted. The mesiodistal width of the anterior teeth was measured at the contact points; the intercanine and interpremolar widths were measured at the cusp tips from the left to the right quadrant; the arc length was measured at the middle one-third position of the crown from the right to the left canine.
\end{abstract}

Results: The results showed that out of the four odontometric parameters, only the arc length was significantly associated with the height of the individuals among the ethnicities chosen.

Conclusion: Thus, of the four selected parameters, the arc length may be helpful in the estimation of stature among the selected Asian ethnicities. Dimensions of the teeth can be used as an adjunct to other aids in estimating the stature of an individual and hence is a vital forensic tool.

Keywords: Asian, Arc length, Ethnicities, Forensic Odontology, Odontometric Parameters, Stature estimation

\section{Background}

Each human is unique, and the measurable characteristics of one individual are seldom similar to another individual. Due to the different characteristics of each human, personal identification can be made regardless of gender, age, race, and ethnicity. Personal proof of identity is a scope where pathology, anthropology, odontology and genetics correlate (Schmitt 2006). Personal identification can be made based on specific features

\footnotetext{
* Correspondence: bharath.rao@manipal.edu

${ }^{1}$ Faculty of Dentistry, Melaka Manipal Medical College, Manipal Academy of

Higher Education, Manipal, India

Full list of author information is available at the end of the article
}

and descriptors, such as the gross features of an individual. The need for personal identification is an essential aspect of forensic sciences. There can be instances where an individual needs to be identified, such as after a genocide, a natural disaster or in cases where a missing individual needs to be matched with the remains of an unknown body that is found after months or years. In routine forensic practice, the identification of a living individual as well as the deceased using skeletal remains and the dentition is of utmost importance. DNA (deoxyribonucleic acid) profiling is an essential tool of the identification process during mass disasters and with 
regard to unidentified individuals. However, DNA testing cannot be employed in all cases.

Anthropometry is the measurement and study of the human body, its parts and capacities (Yadav et al. 2016; Swami et al. 2015). The main aim of anthropometry is to establish the identity of an unknown human to supplement law enforcement agencies. Anthropometric characteristics have a direct correlation with the gender, shape and form of any individual (Stedman 2005). Stature or body height is one of the essential anthropometric parameters that can be used to determine physical identity as it is a distinctly visible factor of an individual. Stature is the height of a person in the upright posture (Patil et al. 2008). When skeletal remains are available and identification is necessary, the most common stature estimates are derived from long bones (Chethan et al. 2019) as various long bones correlate positively with height (Ahmad et al. 2014). However, in cases where the human body is decomposed, fragmented, or mutilated, the proportional biological relationship of stature with other human body parts such as the head, face, trunk and extremities are needed to provide relevant data for personal identification (Wankhede et al. 2012; Özaslan et al. 2003; Garg and Chauhan 2016; Kotian 2013). The study of teeth can enable reliable determination of the stature of a person as teeth are composed mostly of hard tissue, are relatively durable, are chemically the most stable element of the human body, are selectively preserved and fossilized and have resilience in the case of fire and bacterial corrosion (Khangura et al. 2015). Therefore, teeth are usually seen as remains in forensic and archaeological excavations, where not all the bones of an individual are retrieved. This signifies the importance of teeth and other oral structures in the identification of age, sex and race based on odontometric parameters. Few studies have been performed regarding the odontometric measurements in the estimation of the stature or body height (Ahmad et al. 2014; Özaslan et al. 2003; Gupta et al. 2015; Eboh 2016; Dahlberg 1963). Patil et al. (2008) could not establish a correlation between stature and the combined mesiodistal width of the permanent maxillary anterior teeth (Patil et al. 2008). Similar results were obtained in a study by Gupta et al., where the combined mesiodistal width of the permanent maxillary anterior teeth did not help in the estimation of the stature (Gupta et al. 2015). According to Khangura et al., a highly significant correlation was observed between the height of an individual and the intercanine and interpremolar width, whereas the relationship between the height and the combined width of six anterior teeth and the arch length was not significant (Khangura et al. 2015). The present study aimed to estimate stature using odontometric parameters among Asian ethnicities, which included Malay, Indians and Chinese. The studied odontometric parameters were the intercanine width of the maxillary arc, inter premolar width of the maxillary arc, maxillary arc length and mesiodistal dimension of all six maxillary anterior teeth. Thus, the objective of our study was to determine and establish a relationship to estimate the stature of individuals using four odontometric parameters.

\section{Materials and methods}

This study was conducted on 120 subjects who were students pursuing their undergraduate studies at the Melaka Manipal Medical College, Manipal, India. It consisted of 40 individuals from each ethnicity, viz., Malay, Indian and Chinese, with an equal gender distribution. Simple random sampling was followed to select the subjects from each ethnicity. The sample size calculation was based on the significant correlation coefficients reported by Khangura et al. for intercanine width $(r=$ $0.29)$ and interpremolar width $(r=0.35)$ with height (Khangura et al. 2015). Using G*power software version 3.1.2 (Faul et al. 2007), an effect size of 0.29 with an alpha error of $5 \%$ and a power of $95 \%$ yielded a maximum sample size $(n=120)$.

The subjects were finally selected based on the following criteria:

Age range of $18-30$ years

A complete set of fully erupted, periodontally healthy and non-carious, satisfactorily aligned teeth

No history or clinical evidence of cleft palate and cleft lip, orthodontic treatment or trauma

No history or clinical features suggestive of endocrinal disorders, metabolic disorders or history of prolonged illness

Minimal to no wear of the cusp tips of the canines and premolars

The materials used are the following:

Digital Vernier calliper (precision value $\pm 0.01 \mathrm{~mm}$ )
Thread
Metre ruler
Measuring tape
Alcohol swabs
Cotton
Gloves

All subjects were informed about the study and the procedures involved. After obtaining informed consent from each individual, the following five measurements were recorded:

Mesiodistal crown dimension of the six permanent maxillary anterior teeth (SPMAT) 
Intercanine width (ICW)

Interpremolar width (IPMW)

Arc length (AL)

Height of the individual

The mesiodistal width of the crown of the permanent maxillary anterior teeth was measured using a digital Vernier calliper (accurate to $0.01 \mathrm{~mm}$ ) at the level of the contact point between the adjacent teeth at the incisal one-third of the crown. The instrument was held parallel to the occlusal plane, and the mesiodistal width of each maxillary permanent anterior teeth was recorded individually. The combined mesiodistal width of all six maxillary permanent anterior teeth was then obtained by adding individual values. The intercanine width was measured from the cusp tip of the right canine to the cusp tip of the left canine. The interpremolar width was measured at the buccal cusp tip of the right first premolar to the buccal cusp tip of the left first premolar. The centre of the wear facets was estimated in cases of attrition of the cusp tips in canines and premolars, and the measurements were recorded accordingly. The arc length was measured from the middle one-third of the right canine to the middle one-third of the left canine using a clean string, and the length measured was then scaled using a ruler.

The height of each subject was measured from the vertex of the individual's head to the floor using a measuring tape. The height was measured as the subject stood upright on a horizontal resting plane, barefoot, with the measuring tape placed in a vertical position behind the subject (the subject was asked to stand in the anatomical position). A ruler was placed perpendicular to the measuring tape on the vertex of the subject, and the height was recorded.

All the dimensions were measured twice before the final record to minimize errors, and the average of the measurements was taken.

\section{Statistical analysis}

All analyses were performed using SPSS version 18 (SPSS Inc. released 2009. PASW Statistics for Windows, version 18.0. Chicago: SPSS Inc.). A $p$ value of $<0.05$ was considered statistically significant. Pearson's correlation coefficient was used to establish the correlation of odontometric variables with height. Simple linear regression was used to predict height with odontometric variables.

\section{Results}

We found a significant positive correlation between AL and the stature of the individual ( $r=0.287$ and $p=0.002$ ), while no significant correlation was observed between the stature and other odontometric variables (SPMAT, ICW and IPMW) (Table 1). Significant odontometric variables
Table 1 Correlation of height with different odontometric variables

\begin{tabular}{llllll}
\hline & & SPMAT & ICW & IPMW & AL \\
\hline Height & Pearson's correlation coefficient & -0.02 & 0.09 & 0.13 & 0.29 \\
& $p$ value & 0.814 & 0.328 & 0.172 & 0.002 \\
\hline
\end{tabular}

SPMAT mesiodistal crown dimension of the six permanent maxillary anterior teeth, ICW intercanine width, IPMW interpremolar width, $A L$ arc length

were used to predict the stature using simple linear regression analysis. The AL was significantly associated with the stature $(\beta=8.96 ; 95 \% \mathrm{CI}=3.48-14.45)$ of the individuals (Table 2), with an $R^{2}$ of 0.08 .

\section{Discussion}

Identification of an individual from fragmentary remains is an essential aspect of forensic investigations due to an increase in the occurrence of mass disasters. Age, sex and stature are important parameters in establishing the identity of an unknown individual (Hasegawa et al. 2009). Long bones help in the estimation of the stature of an individual as they positively correlate with stature. However, the use of long bones in the case of fragmentary remains is limited (Cesario and Latta 1984). Thus, parameters such as foot length and cranial sutures are being used for stature estimation (Ahmad et al. 2014). Teeth are resistant to damage, and odontometric parameters remain constant over time. Using teeth for identification has several advantages as the anatomical landmarks are standard, well-defined and easy to locate (Franco 2018). Differences in odontometric features in specific and within the same population have made it necessary to obtain values specific to a population for identification based on dental measurements (Doris et al. 1981). Thus, our study evaluated odontometric parameters among three Asian ethnicities: Malay, Indians and Chinese. Doris et al. suggested that an early period of permanent dentition is best suited for tooth size measurements due to minimal mutilation and attrition of the dentition in young adults, thus minimizing the effect of mutilation and attrition on the tooth dimensions (Doris et al. 1981). The achievement of complete skeletal maturity, which is commonly designated as skeletal age (SA), is 18 years (Nahhas et al. 2013); thus, the length (birth to 2 years of age) or height (3-18 years of age) of an individual is defined as short or tall stature (Bramswig 2008). Therefore, subjects in the 18-30 years' age group were included in the study

Table 2 Simple linear regression to evaluate the association of height and arc length

\begin{tabular}{|c|c|c|c|c|c|}
\hline & \multicolumn{2}{|c|}{ Unstandardized coefficients } & \multirow[t]{2}{*}{$T$} & \multirow[t]{2}{*}{$p$ value } & \multirow[t]{2}{*}{$95 \% \mathrm{Cl}$} \\
\hline & $B$ & SE & & & \\
\hline Constant & 125.69 & 12.28 & 10.24 & $<0.001$ & 101.37-150 \\
\hline $\mathrm{AL}$ & 8.96 & 2.77 & 3.24 & 0.002 & $3.48-14.45$ \\
\hline
\end{tabular}

$A L$ arc length, $B$ regression coefficient, $S E$ standard error, $C l$ confidence interval 
sample. Four odontometric parameters, namely, the combined width of six anterior maxillary teeth, intercanine width, interpremolar width and arch length, were evaluated to correlate with the height of an individual.

The use of odontometric parameters for stature estimation is limited. Of the four odontometric parameters selected for the study, Patil et al. in 2008 used the combined width of six maxillary anterior teeth for the estimation of stature and observed a small statistically significant correlation between height and combined mesiodistal width of six anterior maxillary teeth (Patil et al. 2008). However, we concluded that there is no significant correlation between these two parameters. Prabhu et al. in 2013 used the measurements of the crown of the teeth to predict the stature. The proximal and labiolingual widths of the teeth other than the third molars and the heights of the adults were also obtained. There was a significant relationship between the crown of the teeth and the stature of the individual based on a regression analysis for the dentition, thus concluding that the dentition could be used as an adjunct for better and definitive indicators of stature (Prabhu et al. 2013). In our study, odontometric parameters were considered singly with the stature of the individual. Of the four parameters, only the arc length was statistically significant. In a study by Khangura et al. of the four odontometric parameters, intercanine width and interpremolar width were statistically significant in relation to height, which is not in accordance with our study (Khangura et al. 2015).

The equation that was derived using the arc length in our study is

$$
Y=C+\mathrm{MX}
$$

where $Y$ is the predicted stature, $C$ constant of the parameter (125.686), $M$ regression coefficient (8.964) and $X$ arc length (AL).

The selected odontometric parameter can be used singly to estimate the stature of an individual from any of the three Asian ethnicities used in the study. This study proposes the importance of various odontometric parameters as a forensic tool for estimating the stature from fragmentary remains.

\section{Conclusion}

The authors conclude that of the four selected odontometric parameters used, arc length may be used as a tool for stature estimation among Asian ethnicities. Thus, odontometric parameters can be used as reliable tools for predicting the height of an individual. Tooth dimensions can be used as a new approach for the estimation of stature in fragmentary remains. However, further studies are required to estimate the accuracy of predicting the height of an individual using these regression equations for the selected odontometric parameters.

\section{Abbreviations}

C: Constant of the parameter; DNA: Deoxyribonucleic acid; $M$ : Regression coefficient; $X$ : Arc length; $Y: C+M X ; Y$ : Predicted stature

\section{Acknowledgments}

This study was conducted among the medical and dental undergraduate students of Melaka Manipal Medical College, Manipal Academy of Higher Education, Manipal. The authors wish to thank the students who participated in the study. The authors would like to thank Dr. Ullas Kamath, Dean, Melaka Manipal Medical

College for granting permission to conduct the study at the institute.

\section{Authors' contributions}

BRK contributed to the conceptualization. MN and RG contributed to the data curation. SK, RG and PKC contributed to the formal analysis. MN and AS contributed to the methodology. BRK and AA contributed to the project administration. BRK and AS contributed to the writing of the original draft. BRK and RS contributed to the writing, reviewing and editing of the manuscript. All authors read and approved the final manuscript.

\section{Funding}

MAHE, Manipal, and MMMC support this work

Availability of data and materials

Please contact the authors for data requests.

\section{Ethics approval and consent to participate}

This study was conducted with the approval of the Institutional ethics committee of the Manipal Academy of Higher Education (No: 142/2017)

\section{Consent for publication}

Not applicable.

\section{Competing interests}

The authors declare that they have no competing interests.

\section{Author details}

${ }^{1}$ Faculty of Dentistry, Melaka Manipal Medical College, Manipal Academy of Higher Education, Manipal, India. ${ }^{2}$ Manipal College of Dental Sciences, Manipal Academy of Higher Education, Manipal, India.

Received: 6 June 2019 Accepted: 12 November 2019

Published online: 01 December 2019

\section{References}

Ahmad N, Mohd F, Farooque I, Shivkumar BC (2014) Estimation of height from the long bones of lower limb and foot dimensions in south Indian population. J Evid Based Med Healthc 1(8):884-892. https://doi.org/10.18410/ jebmh/2014/135

Bramswig JH (2008) Short and tall stature. Ann Nestle 65(3):117-127. https://doi. org/10.1159/000112234

Cesario VA, Latta GH (1984) Relationship between the mesiodistal width of the maxillary central incisor and interpupillary distance. J Prosthet Dent 52(5): 641-643. https://doi.org/10.1016/0022-3913(84)90133-1

Chethan KN, Zuber M, Bhat NS, Shenoy BS, Kini CR (2019) Static structural analysis of different stem designs used in total hip arthroplasty using finite element method. Heliyon 5(6):e01767. https://doi.org/10.1016/j.heliyon.2019.e01767

Dahlberg AA (1963) Dental traits as identification tools. Dent Prog ;3:155-60

Doris JM, Bernard BW, Kuftinec MM (1981) A biometric study of tooth size and dental crowding. Am J Orthod 79(3):326-336. https://doi.org/10.1016/00029416(81)90080-4

Eboh DEO (2016) Determination of stature from combined maxillary anterior teeth and head dimensions among the Efik and Ibibio of South-South Nigeria. Ann Bioanthropology 4(1):53. https://doi.org/10.4103/2315-7992. 190459

Faul F, Erdfelder E, Lang AG, Buchner A (2007) G*Power 3: a flexible statistical power analysis program for the social, behavioral, and biomedicalsciences. Behav Res Methods 39(2):175-191. https://doi.org/10.3758/BF03193146

Franco A (2018) A colour atlas of forensic dentistry. Rev Bras Odontol Leg No: 107-109. https://doi.org/10.13140/RG.2.1.1903.8808

Garg P. Chauhan S (2016) Determination of stature from the length of head in population of Rajasthan. Int J Med Res Prof 2(2):154-156 
Gupta S, Verma Y, Chandra A, Khanna S, Suhail S (2015) A study on the reliability of combined width of maxillary anterior teeth, maxillary canine width, head circumference, inner canthal distance, inter-alar width and skull diameter in sex and stature determination. Int J Innov Biol Chem Sci 6(February 2016):28-35

Hasegawa I, Uenishi K, Fukunaga T, Kimura R, Osawa M (2009) Stature estimation formulae from radiographically determined limb bone length in a modern Japanese population. Legal Med 11(6):260-266. https://doi.org/10.1016/j. legalmed.2009.07.004

Khangura R, Sircar K, Grewal D (2015) Four odontometric parameters as a forensic tool in stature estimation. J Forensic Dent Sci 7(2):132. https://doi.org/10. 4103/0975-1475.146367

Kotian S (2013) Sexual diamorphism-an odontometric approach. Anthropology $01(02)$. https://doi.org/10.4172/2332-0915.1000104

Nahhas RW, Sherwood RJ, Chumlea WC, Towne B, Duren DL (2013) Predicting the timing of maturational spurts in skeletal age. Am J Phys Anthropol 150(1):68-75. https://doi.org/10.1002/ajpa.22142

Özaslan A, Işcan MY, Özaslan I, Tuğcu H, Koç S (2003) Estimation of stature from body parts. Forensic Sci Int 132(1):40-45. https://doi.org/10.1016/S0379 0738(02)00425-5

Patil K, Mahima V, Kalia S, Shetty S (2008) Stature estimation using odontometry and skull anthropometry. Indian J Dent Res 19(2):150. https://doi.org/10.4103/ 0970-9290.40471

Prabhu S, Acharya AB, Muddapur MV (2013) Are teeth useful in estimating stature? J Forensic Leg Med 20(5):460-464. https://doi.org/10.1016/j.jflm.2013.02.004

Schmitt A (2006) Forensic antropology. In: Medicina

Stedman TL (2005) Stedman's Medical Dictionary. In: Stedman's; Twenty Eighth edition (December 14), vol 0

Swami S, Kumar M, Patnaik WG (2015) Estimation of stature from facial anthropometric measurements in 800 Adult Haryanvi Baniyas. Int J Basic Appl Med Sci 5(1):122-132

Wankhede K, Kamdi N, Parchand M, Anjankar V, Bardale R (2012) Estimation of stature from maxillo-facial anthropometry in a central Indian population. J Forensic Dent Sci 4(1):34. https://doi.org/10.4103/0975-1475.99161

Yadav AB, Yadav SK, Kedia NB, Singh AK (2016) An odontometric approach for estimation of stature in Indians: Cross-Sectional analysis. J Clin Diagn Res 10(3):ZC24-ZC26. https://doi.org/10.7860/JCDR/2016/18406.7386

\section{Publisher's Note}

Springer Nature remains neutral with regard to jurisdictional claims in published maps and institutional affiliations.

\section{Submit your manuscript to a SpringerOpen ${ }^{\circ}$ journal and benefit from:}

- Convenient online submission

- Rigorous peer review

- Open access: articles freely available online

High visibility within the field

- Retaining the copyright to your article

Submit your next manuscript at $\boldsymbol{\nabla}$ springeropen.com 